\title{
Comparative Study of Characteristics of Dye Sensitized Solar Cells Fabricated Using Substrates Coated with Fluorine Doped Tin Oxide and Titanium
}

\author{
Arbin Maharjan \\ Department of Electrical Engineering, Pulchowk Campus, Institute of Engineering, Tribhuvan University \\ Corresponding Email: arbinmaharjandioe.edu.np
}

\begin{abstract}
:
Dye-sensitized solar cells (DSSCs) have attracted many researchers because it has potential to supplement and compete with other solar cell technologies like Silicon $(\mathrm{Si})$ and Cadmium Telluride (CdTe). The fabrication of DSSCs requires a photo electrode and a counter electrode of transparent and conducting nature. The commercial DSSCs uses electrodes of fluorine doped tin oxide (FTO) glass substrates. These electrodes are expensive and hence, possible alternative materials that are cheaper and that would provide better performance under similar environmental condition should be explored. In this paper, titanium (Ti)-coated glass substrates were prepared and then used to prepare electrodes for fabricating DSSCs. Similarly, DSSCs were fabricated using electrodes of conventional FTO-coated glass substrates. Performance characteristics like cell efficiency ( $\eta \%$ ), fill-factor (FF), short circuit current density ( $\mathrm{JSC}_{\mathrm{SC}}$ ) and open circuit voltage (Voc) of both fabricated DSSCs were obtained using their respective J-V characteristic curves under similar illumination of $100 \mathrm{~mW} / \mathrm{cm}^{2}$ and with comparable transmittance under the visible transmission spectrum of 300-850 $\mathrm{nm}$. The obtained results showed that DSSCs prepared using electrodes of FTO coated glass substrates have 1.557 times better cell efficiency and 2.172 times better fill factor than that of DSSCs fabricated using electrodes of Ti-coated glass substrates.
\end{abstract}

Keywords: Dye Sensitized Solar Cell, Fluorine Doped Tin Oxide, Titanium, Characteristics Curve, Efficiency, Fill Factor

\section{Introduction}

In 1991, Grätzel and O'regan reported the first dye sensitized solar cell with a cell efficiency of $7-8 \%$. Since then, it has evolved as a promising third generation solar cell technology with potential to supplement and complete with other existing technologies like Silicon and Cadmium Telluride [1]. Conventional DSSCs prepared in lab with electrodes of FTO-coated substrates have low efficiency $\sim 10 \%$, short operating life span of 3-5 years and

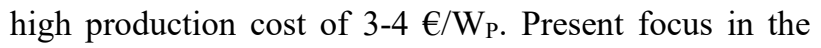
development of DSSCs is to find out new conductive cell materials that would generate higher efficiency, longer operating life with lower production costs.

Transparent and conducting thin film substrates cover most of the production cost in a dye sensitized solar cell. Thin films of Indium doped tin oxide (ITO) coated glass substrates have to be replaced due to low availability of indium (In), high production cost of $1.7 € / \mathrm{cm}^{3}$ and their brittle nature. Similarly, FTO coated glass substrates face problems of etching and their production cost is 1.048 $€ / \mathrm{cm}^{3}[2]$. Apart from that, Tin and Indium are toxic and hence, this contributes to their increased processing cost and should be prevented from contamination with the environment. Considering all these drawbacks there is definitely an increasing demand for alternative transparent and conducting thin film materials that are cost effective, lighter in weight, mechanically durable and thermally stable.

Metal Titanium (Ti) is fourth most abundant material with very light weight and low cost $(\mathrm{Ti}<\mathrm{Sn}<\mathrm{In})$. Also, they are less toxic than $\mathrm{Sn}$ or $\mathrm{In}(\mathrm{Ti}<\mathrm{Sn}<\mathrm{In})$ and hence requires low processing cost making it suitable for larger area solar cells. It is mechanically strong at low moderate temperature $\sim 350^{\circ} \mathrm{C}$ and corrosion resistant to oxidizing acids, iodides and alkalis [3]. These properties of Ti are vital advantages for DSSCs for their better performance.

This experiment is an effort to investigate the feasibility of ultra-thin films of transparent and conducting Ticoated glass substrates as an alternative to FTO coated substrates as the electrodes for fabrication a DSSCs. Sheet resistance and transparency of the Ti-coated substrates were obtained and then used to prepare electrodes necessary after DSSCs fabrication. DSSCs using electrodes of conventional FTO-coated glass substrates were fabricated as well. Finally, the Performance parameters like cell efficiency $(\eta)$, fill factor (FF), open circuit voltage $\left(\mathrm{V}_{\mathrm{OC}}\right)$ and short circuit current density $\left(\mathrm{J}_{\mathrm{SC}}\right)$ 
of these DSSCs were obtained compared under similar illumination and transparency.

\section{Theoretical Background}

Dye sensitized solar cell is an electrochemical device that uses light absorbing dye molecules adsorbed on semiconductor nanoparticles commonly titanium dioxide $\left(\mathrm{TiO}_{2}\right)$ to generate electricity from sunlight as shown in Fig 1. It consists of two transparent conducting oxide (TCO) covered glasses or plastic substrates working as electrodes. Photo electrode (PE) is deposited with mesoporous $\mathrm{TiO}_{2}$ film covered with dye molecules [example: cis-(NCS) $)_{2}$ (2, 2'-bipyridl-4,4'dicarboxylate) $)_{2}$ $\mathrm{Ru}(\mathrm{II})]$ ( $\mathrm{N}_{3}$ dye, commonly called red dye). Counter electrode (CE) is deposited with platinum (or carbon) catalyst. The interface between two electrodes is filled with organic electrolyte containing a redox pair [tri-iodide $\left(\mathrm{I}_{3}^{-}\right) /$iodide $\left.\left(\mathrm{I}^{-}\right)\right]$in an organic solvent like 3-methoxy propionitrile (MPN) and edges of both electrodes is sealed together with a thermoplastic polymer film also called surlyn.

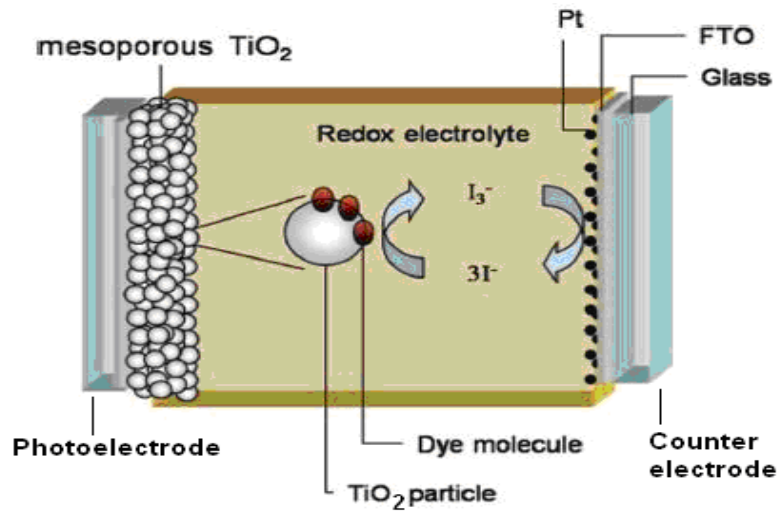

Figure 1: Schematic diagram of a dye sensitized solar cell

[1]

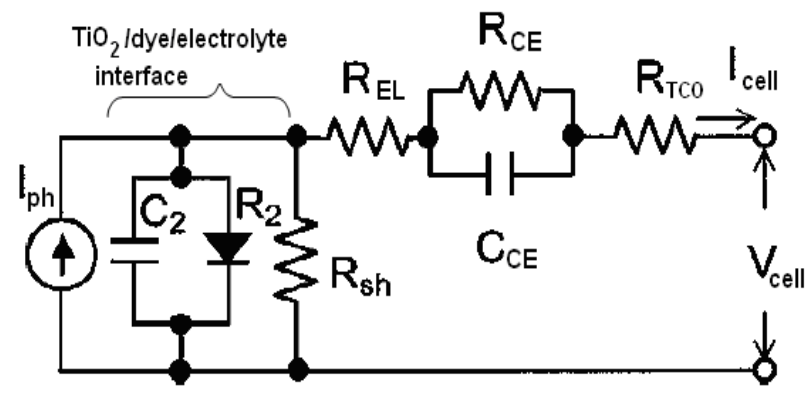

Figure 2: Equivalent circuit of a dye sensitized solar cell [4]

Where,

$\mathrm{R}_{2}=$ resistance offered by diode

$\mathrm{R}_{\mathrm{Sh}}=$ shunt resistance $=\infty$

$\mathrm{C}_{2}=$ capacitance offered by $\mathrm{TiO}_{2} /$ dye/electrolyte interface
$\mathrm{R}_{\mathrm{CE}}=$ Charge transfer resistance at counter electrodeelectrolyte interface $\left(\Omega . \mathrm{cm}^{2}\right)$

$\mathrm{C}_{\mathrm{CE}}=$ capacitance offered by Pt/electrolyte interface

$\mathrm{R}_{\mathrm{EL}}=$ Resistance offered by the electrolyte $\left(\Omega . \mathrm{cm}^{2}\right)$

$\mathrm{R}_{\mathrm{TCO}}=$ Resistance offered by the conducting substrate $\left(\Omega . \mathrm{cm}^{2}\right)$

$\mathrm{V}_{\text {cell }}=$ Output cell voltage

$\mathrm{I}_{\mathrm{ph}}=$ Generated photo current and

$\mathrm{I}_{\text {cell }}=$ Cell current

Fig. 2 shows the equivalent electrical circuit model based on electrochemical impedance spectroscopy which fits best for DSSCs. This model clearly shows the effect of voltage drops taking place at various components of DSSCs on their J-V characteristic curve.

\subsection{Operating Principle}

Considering various reactions taking place at different components of dye sensitized solar cell its operating principle can be explained.

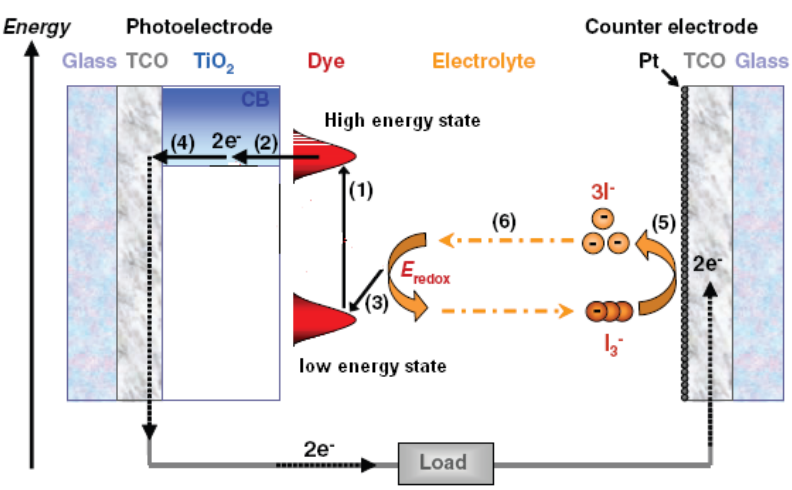

Figure 3: Dye sensitized solar cell showing different chemical reactions responsible for its operation [5]

\section{Photo electrode}

When sunlight strikes the semiconducting oxide $\left(\mathrm{TiO}_{2}\right)$ on photo electrode, dye adsorbed on $\mathrm{TiO}_{2}$ absorbs a photon which excites an electron from low to high energy state. Excited electron is then injected to the conduction band of $\mathrm{TiO}_{2}$ and oxidized dye is regenerated by capturing electron from the redox electrolyte. Finally, electron from $\mathrm{TiO}_{2}$ gets transported to the conducting substrate of photo electrode by diffusion. These processes can be represented with the following reaction equations.

$$
\begin{array}{cr}
S+h v \longrightarrow S^{*} \quad \text { light absorption by the dye } \\
S^{*} \longrightarrow S^{+}+e^{-}\left(\mathrm{TiO}_{2}\right) & \text { electron injection } \\
2 S^{+}+3 I^{-}(\mathrm{PE}) \longrightarrow 2 S+I_{3}^{-}(\mathrm{PE}) & \text { dye regeneration } \\
e^{-}\left(\mathrm{TiO}_{2}\right) \longrightarrow e^{-}(\mathrm{PE}) & \text { electron transport }
\end{array}
$$

\section{Counter electrode}


With the help of external electrical circuit, electron is transferred from photo electrode to substrate of counter electrode where, platinum $(\mathrm{Pt})$ helps in enhancing overall electron transfer between counter electrode and electrolyte [5]. Pt helps in reducing charge transfer resistance of counter electrode from $10^{6}$ to $(0.8$ to 11$)$ $\Omega / \mathrm{cm}^{2}[6]$. The dissociation of iodine also takes place at Pt surface.

$$
I_{3}^{-}(C E)+2 e^{-}(C E) \longrightarrow 3 I^{-}(C E)
$$

Overall charge transfer reaction

\section{Electrolyte}

Electrolyte helps in completing circuit of DSSC by ionic transport of the redox pair minimizing electron transport problem between photo electrode and counter electrode. Electrolyte used should be chemically stable, have low viscosity and be a good solvent for redox couple components and various additives like 4-tertbutylpyridine (4-TBP), 1-methlybenzimidazole (MBI) and 3-methoxypropionitrile (3-MPN) but at the same time not causing dissolution of absorbed dye. 4-TBP and MBI shifts the conduction band edge toward higher energies and reduces recombination providing high performance [7].

$$
\left.\begin{array}{r}
3 I^{-}(C E) \longrightarrow 3 I^{-}(P E) \\
I_{3}^{-}(P E) \longrightarrow I_{3}^{-}(C E)
\end{array}\right\} \quad \begin{array}{r}
\text { Iodide and tri-iodide } \\
\text { diffusion }
\end{array}
$$

Thus, total circuit reactions can be summarized with following equations.

$$
\left.\begin{array}{c}
3 I^{-}(P E)+2 h v \longrightarrow I_{3}^{-}(P E)+2 e^{-}\left(\mathrm{TiO}_{2}\right) \\
\mathrm{e}^{-}(\mathrm{CE})+\mathrm{hu} \longrightarrow \mathrm{e}^{-}(\mathrm{PE})
\end{array}\right\} \begin{array}{r}
\text { Photo electrode } \\
\text { cell }
\end{array}
$$

\subsection{Characterization of DSSC}

Dye sensitized solar cell is usually characterized by using performance parameters like power conversion efficiency $(\eta)$, fill factor $(\mathrm{FF})$, short circuit current density $\left(\mathrm{J}_{\mathrm{SC}}\right)$ and open circuit voltage $\left(\mathrm{V}_{\mathrm{OC}}\right)$ obtained from its current density versus cell voltage $(\mathrm{J}-\mathrm{V})$ characteristic curve.

Power conversion efficiency is the ratio of maximum power produced by cell at maximum power point to power of stimulated illumination.

$$
\eta=\frac{\mathrm{P}_{\text {actual }}}{\mathrm{P}_{\text {illumination }}}=\frac{V_{M P P} * I_{M P P}}{\mathrm{P}_{\text {illumination }}}
$$

Fill factor (FF) is the ratio of actual and theoretical maximum power outputs of the cell. It is always $\leq 1$ and it indicates how square the $\mathrm{J}-\mathrm{V}$ curve is.

$$
F F=\frac{P_{\text {actual }}}{P_{\text {theoritical }}}=\frac{P_{\text {max }}}{V_{O C} \times J_{S C}}
$$

$$
F F=\frac{\eta * \mathrm{P}_{\text {illumination }}}{V_{O C} * J_{S C}}
$$

$\mathrm{V}_{\mathrm{OC}}$ is the light intensity dependent rest potential or open circuit voltage of the cell obtained at $\mathrm{J}=0$ and $\mathrm{J}_{\mathrm{SC}}$ is maximum current density obtained at zero cell voltage i.e. at $\mathrm{V}=0$.

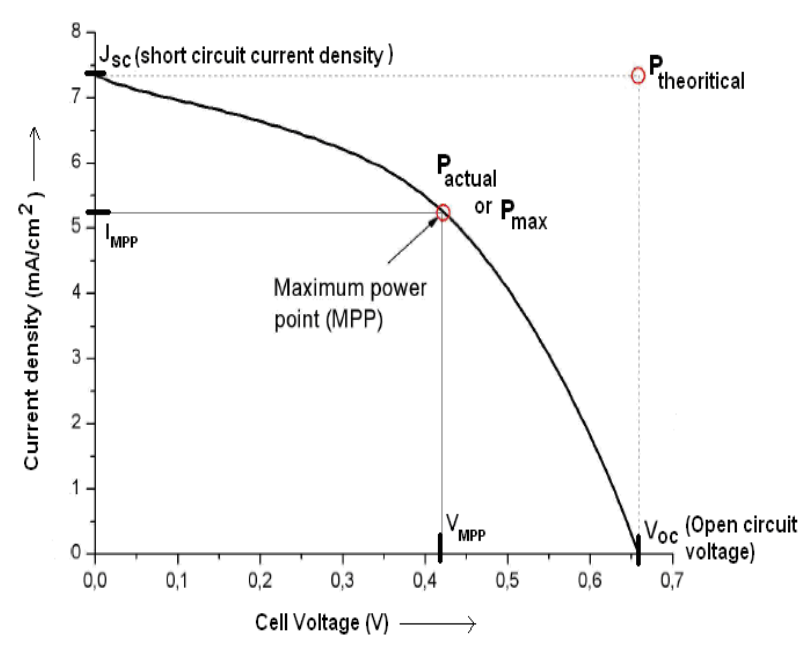

Figure 4: J-V characteristics of a typical dye sensitized solar cell [7].

\section{Experiment}

\subsection{Deposition of Ti-films onto glass substrate}

Microscopic glass substrates were cleaned with 2\% RBS25 detergent solution then was sonicated for 10 minutes and rinsed with ion-exchanged water that removes any detergents and also with isopropanol that remove oils and organic residues left on the glass substrate [8]. Thin films of Ti were deposited on these substrates with film thicknesses of $8 \mathrm{~nm}$ and $15 \mathrm{~nm}$ using ultra high v acuum (UHV) evaporation technique at a rate of $1 \AA / \mathrm{s}$ and maintaining a pressure of about $2 \times 10^{-8}$ mbar.

\subsection{Fabrication of Dye-sensitized solar cell}

Following steps were done for the fabrication for DSSCs:

Step 1: Photoelectrode (PE) was prepared on 15nm thick Ti-substrate by depositing 80-120 $\mu$ litanium dioxide paste $\left(\mathrm{TiO}_{2}\right)$ within an area of $1 \mathrm{~cm}^{2}$ using simple Doctor Blading technique with a tape thickness of $6 \mu \mathrm{m}$. It was then left to dry for an hour and annealed using a hot-air gun at $400^{\circ} \mathrm{C}$ for 30 minutes to remove any organic components or polymers.

Step 2: Counter electrodes (CE) was prepared on $15 \mathrm{~nm}$ thick Ti-substrate by thermal decomposition of $30 \mu \mathrm{l}$ platinum chloride, $\left(\mathrm{H}_{2} \mathrm{PtCl}_{6}\right)$ over a hot plate heated at 
$350^{\circ} \mathrm{C}$. It was then then sintered at $390^{\circ} \mathrm{C}$ for 30 minutes to evaporate any alkali oxides or peroxides and to maintain good adhesion between Pt and the substrate.

Step 3: Prepared PE was sensitized in a $0.3 \mathrm{mM}$ dye solution containing $4.4 \mathrm{mg}( \pm 0.1 \mathrm{mg})$ of 2, 2'-bipyridyl-4, 4'-dicarboxylic acid [RuL2(NCS)2] also known as Red dye (N3 dye) for about 24 hours.

Step 4: Prepared PE and CE were attached together by gently pressing in between heated plates at $95^{\circ} \mathrm{C}$ with the help of $15 \mathrm{~mm} \times 15 \mathrm{~mm}$ (with $1 \mathrm{~cm}^{2}$ opening) surlyn frame (Du Pont) as such that, $\mathrm{Pt}$ on $\mathrm{CE}$ and sensitized $\mathrm{TiO}_{2}$ on PE faced each other in between the opening. $15 \mu 1$ electrolyte was then poured using a pipette tip onto the gap through hole on CE. For this, cell (along with the pipette tip containing electrolyte) was kept inside a vacuum chamber at a pressure of 1 atmosphere and then pumped to $\sim 1$ mbar. This drop in pressure caused air to escape from the cell with vigorous up and down movement of electrolyte. When the normal pressure was restored, electrolyte passed onto the interface between $\mathrm{Pt}$ and $\mathrm{TiO}_{2}$. This process was repeated whenever electrolyte failed to fill the gap. Hole on counter electrode was finally sealed using surlyn frame in order to block leakage of electrolyte.

Step 6: Silver (Ag) contacts were made onto the conductive surface of the electrodes in order to enhance electrical contacts between conductive layer (Ti) and clamps in the J-V measurement setup.

Similar steps were followed to fabricate a DSSC using commercially available FTO coated glass substrates having sheet resistance of $10 \Omega / \square$ and transmittance of $80 \% \mathrm{~T}$ for obtaining its $\mathrm{J}-\mathrm{V}$ characteristics.

\section{$4 \quad$ Results and Discussions}

\subsection{Sheet Resistance}

Sheet resistances of Ti-coated glass substrates before and after annealing were measured using four-point Vander Pauw technique. Sheet resistance obtained for $8 \mathrm{~nm}$ thick Ti-coated substrate was $198.2 \Omega / \square$ which is very high and hence was neglected for fabricating the DSSCs.

Sheet resistances were found to decrease from $198.2 \Omega / \square$ to $72.25 \Omega / \square$ on increasing thickness from 8 to $15 \mathrm{~nm}$. This is due to improved crystalline structure or larger grains of thicker films which reduced the grain boundary scattering (or loss of carriers) and hence, increased the carrier concentration giving high conductance or low resistance [9].
On annealing the $15 \mathrm{~nm}$ thick substrate, the sheet resistance was increased from $72.25 \Omega / \square$ to $236.919 \Omega / \square$, increase in sheet resistance is due to the formation of nonhomogeneous and discontinuous layer of titanium dioxide $\left(\mathrm{TiO}_{2}\right)$ due to the diffusion of oxygen in titanium lattice [10]. Fig. 5 shows the corresponding SEM images before and after annealing the $15 \mathrm{~nm}$ thick Ti-coated substrates.

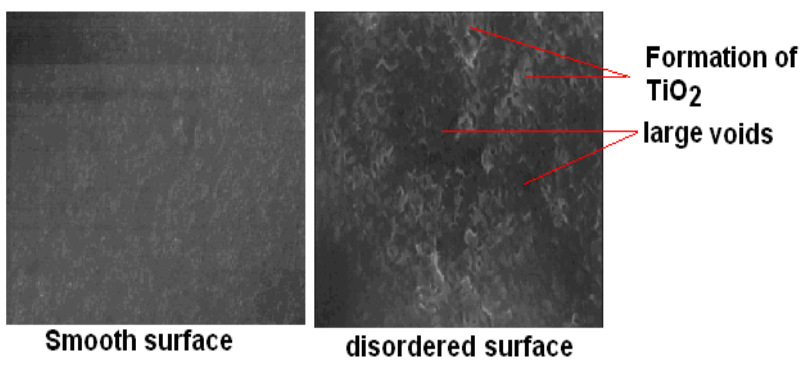

Figure 5: SEM images of $15 \mathrm{~nm}$ thick Ti-coated substrate, before annealing (left) and after annealing (right)

\subsection{Transmission Spectra}

Transmission spectra at visible region from 300 to $850 \mathrm{~nm}$ were taken using Perkin Elmer Lambda 850, UV/VIS spectrometer. Fig. 6 shows the transmission spectra of Ticoated glass substrates before and after annealing at 400 ${ }^{\circ} \mathrm{C}$. It can be seen that the transmittance was increased from $14 \%$ before annealing to $26 \%$ after annealing. This increase in transmittance is due to the non-homogenous layer of $\mathrm{TiO}_{2}$ creating voids [9].

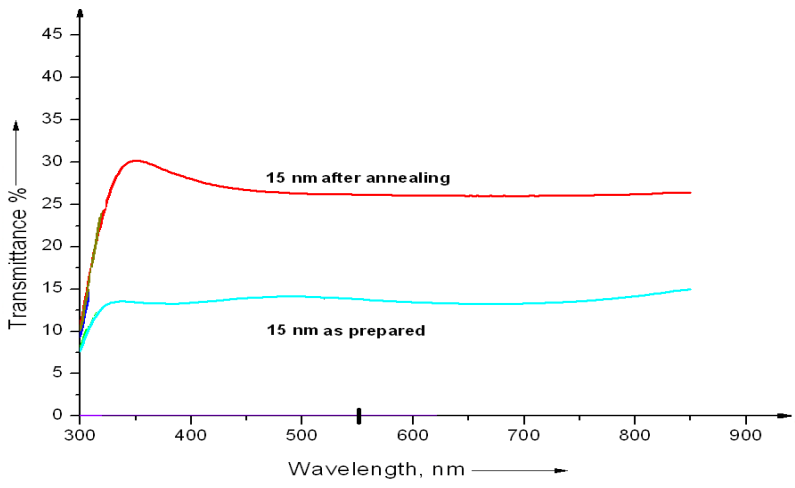

Figure 6: Transmission spectra for $15 \mathrm{~nm}$ thick Ti-coated substrate before and after annealing at $400^{\circ} \mathrm{C}$

Transmittance of FTO coated substrates was made similar to that of $15 \mathrm{~nm}$ thick Ti-coated substrates $(\sim 26 \% \mathrm{~T})$ using filters of $0.4 \mathrm{~T}$ which decreased the transmittance from $80 \% \mathrm{~T}$ to $32 \% \mathrm{~T}$.

\subsection{Current density versus cell voltage (J- V) characteristics}




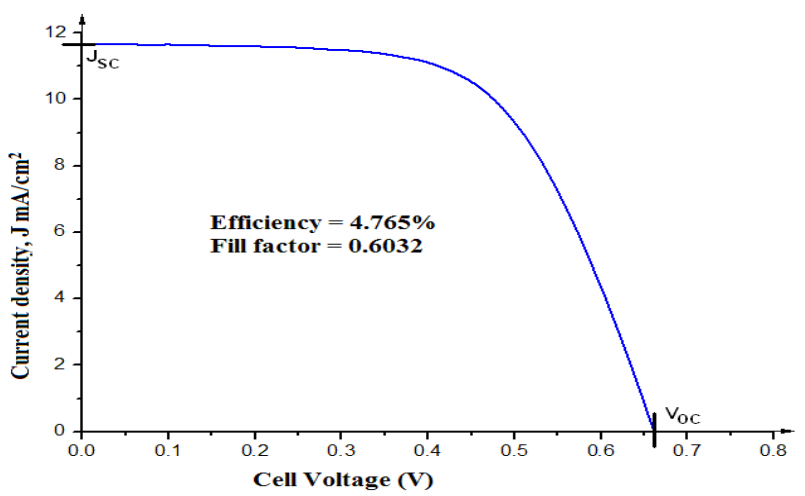

Figure 7: J-V characteristic of fabricated DSSC using electrodes of FTO coated glass substrate (without filter)

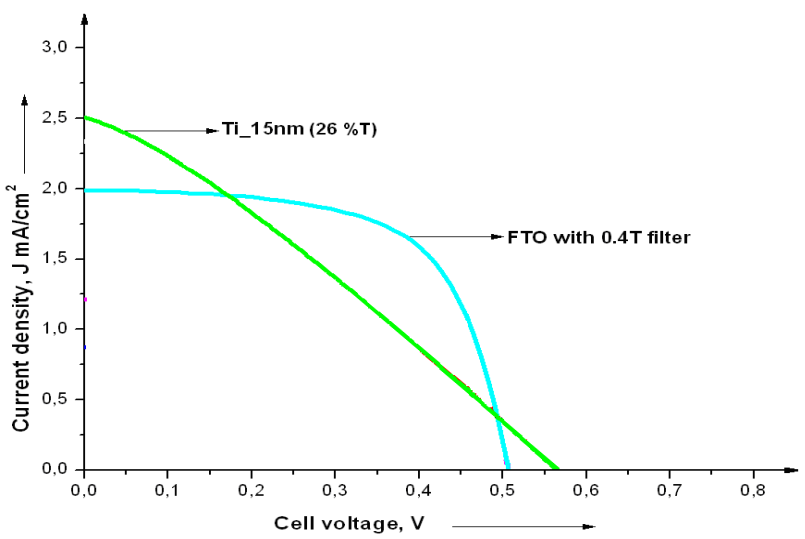

Figure 8: J-V characteristic of DSSC prepared using electrodes Ti and FTO coated substrate under similar illumination and transparency

$\mathrm{J}-\mathrm{V}$ characteristics of prepared DSSCs were measured using digital source meter from Keithley Instrument Inc, Model No. 2400 under the stimulated illumination of 100 $\mathrm{mW} / \mathrm{cm}^{2}$ with an aperture mask area of $0.5 \mathrm{~cm}^{2}$ to reduce reflection and scattering of light [10]. Voltage sweeps in both normal (-1 to $1 \mathrm{~V})$ and reverse $(1$ to $-1 \mathrm{~V})$ direction was done at a sampling delay time of $10 \mathrm{~ms}$ for all DSSCs prepared using FTO (with and without $0.4 \mathrm{~T}$ filter) and $15 \mathrm{~nm}$ thick Ti-coated glass substrates. The average value of the performance characteristics was obtained to minimize the error [11].

For DSSC prepared using electrodes of FTO coated glass substrate (without filter), good cell efficiency of $4.765 \%$ and a fill factor of 0.6 was obtained which is due to high short current density $\left(11.66 \mathrm{~mA} / \mathrm{cm}^{2}\right)$ and low sheet resistance $(10 \Omega / \square)$ supported by high transmittance $(80 \% \mathrm{~T})$.

Figure 8 shows a comparison of obtained J-V characteristic of DSSCs prepared using electrodes of FTO coated substrate (with $0.4 \mathrm{~T}$ filter) and $15 \mathrm{~nm}$ thick Ticoated substrates under similar illumination and transparency.
The performance parameters obtained from J-V characteristics are presented in table 1.

Table 1: Performance parameters

\begin{tabular}{|l|l|l|l|l|l|}
\hline Sample & $\mathbf{\%} \mathbf{T}$ & $\begin{array}{l}\mathbf{V}_{\text {OC }} \\
(\text { Volts })\end{array}$ & $\begin{array}{l}\mathbf{J}_{\text {SC }} \\
(\mathbf{m A} / \mathbf{c m})^{2}\end{array}$ & FF & $\boldsymbol{\eta} \%$ \\
\hline FTO with 0.4T filter & 32 & 0.504 & 1.987 & 0.63 & 0.637 \\
\hline Ti-2 $(15 \mathrm{~nm})$ & 26 & 0.562 & 2.5 & 0.29 & 0.409 \\
\hline
\end{tabular}

From table 1, it can be seen that when the transmittance of DSSC prepared from FTO (with 0.4T filter) was brought down to $32 \% \mathrm{~T}$, there was a significant reduction in cell efficiency from $4.765 \%$ to $0.637 \%$ with the fill factor of 0.636 . This is due to significant decrease in short circuit current density value from $11.66 \mathrm{~mA} / \mathrm{cm}^{2}$ to 1.987 $\mathrm{mA} / \mathrm{cm}^{2}$. Whereas, in case of DSSC prepared from electrodes of Ti-coated substrates, the cell efficiency was only $0.409 \%$. This is due to low fill factor of 0.29 caused by very low value of $\mathrm{V}_{\mathrm{MPP}}$ as seen in fig 8 .

\section{Conclusion}

Thus, Ti-coated glass substrates were prepared using UHV deposition technique and their sheet resistances were measured using four-point Vander Pauw technique. Similarly, their transmittances were measured using Perkin Elmer Lambda 850, UV/VIS spectrometer. The transmittance of commercially available FTO glass substrates, $80 \% \mathrm{~T}$ were reduced to $32 \% \mathrm{~T}$ using a filter of $0.4 \mathrm{~T}$ in order to make its transmittance similar to that of $15 \mathrm{~nm}$ Ti-coated glass substrates $(26 \% \mathrm{~T})$. DSSCs were fabricated using the electrodes prepared from both FTO and $\mathrm{Ti}$ coated glass substrates. Performance characteristics or $\mathrm{J}-\mathrm{V}$ characteristics curve of both fabricated DSSCs were obtained using digital source meter from Keithley Instrument Inc, Model 2400 under a stimulated illumination of $100 \mathrm{~mW} / \mathrm{cm}^{2}$ in an aperture mask area of $0.5 \mathrm{~cm}^{2}$ to reduce the reflection and light scattering. Finally, performance parameters like cell efficiency $(\eta)$, fill factor, $\mathrm{J}_{\mathrm{SC}}$ and $\mathrm{V}_{\mathrm{OC}}$ were obtained from their respective $\mathrm{J}-\mathrm{V}$ characteristic curves and were compared. Results showed that DSSCs prepared using electrodes of FTO coated glass substrates have better cell efficiency and fill factor than that of DSSCs prepared using Ti-coated glass substrates.

\section{References}

[1] Hagfeldt, G. Boschloo and L. Sun et. al, "DyeSensitized Solar Cells," Chem, Rev, vol no. 110, pp. 6595-6663, 2010. 
[2] R. G. Gordon, "Criteria for choosing transparent conductors," 2000.

[3] “Corrosion resistance of titanium," TIMET (Titanium Metals Corporation), 1997.

[4] L. Han, N. Koide and Y. Chiba et. al, "Improvement of efficiency of dye-sensitized solar cells by reduction of internal resistance," Applied physics, vol. 86, pp. 213501213503, 2005.

[5] J. Halme, P. Vahermaa and K. Miettunen et. al, "Device physics of dye solar cells," Advanced energy materials, vol. 22, pp. E210-E234, 2010.

[6] K. Aitola, J. Halme and N. Halonen, "Comparison of dye solar cell counter electrodes based on different carbon nanostructures," Thin solid films, vol. 519, pp. 8125-8134, 2011.

[7] N. Koide and L. Han, "Measuring methods of cell performance of dye-sensitized solar cells," Review of scientific instruments, vol. 75, no. 9, pp. 2828-2831, 2004.

[8] A. Purwanto, H. Widiyandari and A. Jumari, "Fabrication of high-performance fluorine doped-tin oxide film using flame-assisted spray deposition," Thin Solid films, vol. 520, pp. 2092-2095, 2012

[9] X. Huang, Z. Yu and S. Huang et. al, "Preparation of fluorine-doped tin oxide $\left(\mathrm{SnO}_{2}: \mathrm{F}\right)$ film on polyethylene terephthalate (PET) substrate," Materials letters, vol. 64, pp. 1701- 1703, 2010.

[10] J. Ederth, P. Johnson and G.A. Niklasson et. al, "Electrical and optical properties of thin films consisting of tin-doped indium oxide nanoparticles," Physical review B, vol. 68, pp.155410, 2003.

[11] F. F. Santiago, J. Bisquert and G. G. Belmonte et al, "Influence of electrolyte in transport and recombination in dye-sensitized solar cells studied by impedance spectroscopy," Solar energy materials and solar cells, vol. 87, pp. 117-131, 2005. 